\title{
Evaluation of the Impact of the Tiny Earth Project on the Knowledge About Antibiotics of Pre-university Students in the Province of Valencia on Three Different School Years (2017-2020)
}

\author{
Jose I. Bueso-Bordils ${ }^{1}$, Beatriz Suay-García ${ }^{2}$, Carolina Galiana-Roselló ${ }^{1}$, \\ Elisa Marco-Crespo ${ }^{3}$ and María-Teresa Pérez-Gracia ${ }^{1 *}$
}

'Departamento de Farmacia, Universidad Cardenal Herrera-CEU, Valencia, Spain, ${ }^{2}$ ESI International Chair@CEU-UCH, Departamento de Matemáticas, Física y Ciencias Tecnológicas, Universidad Cardenal Herrera-CEU, Valencia, Spain,

${ }^{3}$ Departamento de Comunicación e Información Periodística, Universidad Cardenal Herrera-CEU, Valencia, Spain

OPEN ACCESS

Edited by:

Davida Smyth,

The New School, United States

Reviewed by:

Mariana Carmen Chifiriuc, University of Bucharest, Romania

Olga Calderon,

LaGuardia Community College,

United States

*Correspondence:

María-Teresa Pérez-Gracia teresa@uchceu.es

Specialty section:

This article was submitted to

Systems Microbiology,

a section of the journal

Frontiers in Microbiology

Received: 25 June 2020 Accepted: 27 October 2020 Published: 19 November 2020

Citation:

Bueso-Bordils JI, Suay-García B, Galiana-Roselló C, Marco-Crespo E and Pérez-Gracia M-T (2020) Evaluation of the Impact of the Tiny Earth Project on the Knowledge About Antibiotics of Pre-university Students in the Province of Valencia on Three Different School Years (2017-2020).

Front. Microbiol. 11:576315. doi: 10.3389/fmicb.2020.576315
According to the World Health Organization (WHO), antibacterial resistance is a serious problem worldwide. In Spain, knowledge about the use of antibiotics is scarce, being the third country with the highest consumption of antibiotics in the world and the first in Europe. This problem is due, partly, to the abusive use of these drugs in human medicine, livestock, and agriculture. The objective of this study was to evaluate the impact that the Tiny Earth project has had on the antibiotic knowledge in pre-university students. To do this, a survey was conducted before and after the Tiny Earth project in three different school years (2017-2020) to 322 pre-university students belonging to seven schools in the province of Valencia. The survey consisted of 12 multiple-choice questions with a single valid answer. We observed $67.6 \%$ success at the beginning and $81.2 \%$ at the end. These data indicate that they correctly answered an average of 1.64 more questions after completing the project. In view of the results, we can affirm that the Tiny Earth project has contributed to an improvement in scientific knowledge and awareness of the correct use of antibiotics and the emergence of resistances by pre-university students, which could also be transmitted to their social environment, thus improving awareness global on these issues.

Keywords: Tiny Earth, resistances, antibiotics, rational use, global awareness, knowledge surveys, citizen science

\section{INTRODUCTION}

Antibacterial resistance has become a serious health problem worldwide (Prigitano et al., 2018) and is now spreading faster in comparison to the development of new molecules. It should be noted that only 8 of the 33 new antibiotics in development belong to new families, a small number considering the large number of bacterial resistances we are facing (Lewis, 2017). In fact, according to WHO, bacterial resistances will be the leading cause of death in 2050 and the biggest challenge in the field of Biomedicine in the 21st century (World Health Organization, 2016). 
In Spain, knowledge about the use of antibiotics is scarce, being the third country with the highest consumption of antibiotics in the world and the first one in Europe (Klein et al., 2018). This problem is due, in part, to the misuse of these drugs in human medicine, livestock, and agriculture (Phillips et al., 2004). This problem is even more serious if we bear in mind that three quarters of the antimicrobial agents used in livestock overlap with antimicrobials used in humans (O'Neill, 2015). This has led to the so-called "antibiotic crisis," result of the shared irresponsibility of health professionals, politicians, and consumers of antibiotics themselves, though in very different degrees of responsibility (Cisneros Herreros and Peñalva Moreno, 2018).

In this context, it seems important to promote educational initiatives on the proper use and prescription of antimicrobial drugs (Scaioli et al., 2015). Following this line of action, Tiny Earth (2018) appears as an innovative project of citizen, participatory, educational, and social science based on a crowdsourcing strategy for the exploration of microbial biodiversity in soils in search of new antibiotic-producing microorganisms (Valderrama et al., 2018). Motivation is reinforced by the fact that there already exist compounds described as antibacterials produced by microorganisms isolated from soil, namely malacidins and teixobactin (Hover et al., 2018). In this way, it motivates pre-university students toward choosing a scientific degree while addressing a global health threat such as the resistance of bacteria to antibiotics (Handelsman et al., 2016; Pernaute and Jiménez, 2017).

A crowdsourcing strategy involves outsourcing tasks, rather than being performed by institution staff, overseeing a large group of volunteers or community through an open call. The idea of crowdsourcing is relatively recent, it shares the perspective defended by some academic sectors of free and open access to scientific knowledge (Open Access) and benefits from advances in communication technologies (internet and social networks). It has been postulated for use in the field of Public Health and other aspects related to Biomedicine (Brabham et al., 2014; Bentzien et al., 2015) and, applied to the educational environment, can provide a collaborative and practical dimension that is highly motivating for students (Caruso et al., 2016).

At the same time that it instructs and motivates, Tiny Earth alerts, reports and raises awareness to society and future generations. It invites pre-university students to participate in a real international project that addresses a very relevant health issue such as the lack of effective antibiotics to fight the infections caused by multi-resistant bacteria, which are already immune to virtually our entire therapeutic arsenal (Davies and Davies, 2010). Throughout the lab lessons, the Tiny Earth program focuses on the idea of discovery, in which students from around the world carry out creative fieldwork and laboratory research on soil samples in search of new antibiotic-producing microorganisms (Davis et al., 2017).

The implantation for the first time at the CEU Cardenal Herrera University (CEU UCH), sponsored by the Spanish Microbiology Society within the D+D group, of the successful educational and informative project of American origin Tiny Earth raises an important and original novelty compared to the United States project. It involves integrating two educational levels, pre-university and university, by implementing an ambitious strategy of service learning, which implies that the teaching activities and strategies used in the training of university students must have a direct impact on the community and society, integrating concepts of active learning, practical teaching, group work, and social volunteering. Indeed, the learning aspect of this project is not limited to the knowledge that pre-university students can acquire, since university students also acquire a series of new skills related to their knowledge transmission skills, teamwork, lab work, and expertise on the subject of antibacterial resistance.

To launch the Tiny Earth project, we recruited undergraduate students who had already taken courses in the field of Microbiology and students in the field of Communication Degrees in various degrees of the CEU UCH, to highlight the importance of divulgation and scientific communication and raise awareness about this health issue. This project was carried out in five private and state-funded schools in the province of Valencia during the first year (2017-2018). The project was expanded the second year (2018-2019) to include two more schools. In its third year (2019-2020), the schools remained the same.

The aim of this study is to evaluate the impact that the Tiny Earth project has had on the knowledge about antibiotics of the participating pre-university students. The results of our survey, which involved people of a very narrow age range, cannot be extended to the entire Spanish population. Nevertheless, they provide valid elements to promote initiatives aimed at a more conscious use of antibiotics.

\section{MATERIALS AND METHODS}

The Tiny Earth project consists of five practical sessions, challenging young students to discover novel bioactive-producing microorganisms from soil samples as well as raising awareness about antibiotic resistance and their appropriate use. Throughout 3 academic years, 19 Tiny Earth teams, each consisting of three to five undergraduate students or Tiny Earth Teaching Assistants (Tiny Earth TAs) led by one University teacher or Tiny Earth Partner Instructor (Tiny Earth PI).

To evaluate the pedagogical impact of the project, 322 pre-university students filled in a survey at the beginning (practical 1) and at the end (practical 5) of their participation in the Tiny Earth project, which consisted of 12 multiplechoice questions with one correct answer. We wrote this survey in Spanish and English (Figure 1) and we handed it out in one language or the other, depending on the school. The aim of this survey was to assess the level of knowledge about the appropriate use of antibiotics and the level of perception regarding the problem of antibiotic resistances. This survey was prepared based on questions asked by Tiny Earth TAs and Tiny Earth PIs who participated in the project.

Unlike other studies in which respondents were required to provide certain personal data for further demographic analysis (World Health Organization, 2015), in our case, we decided 


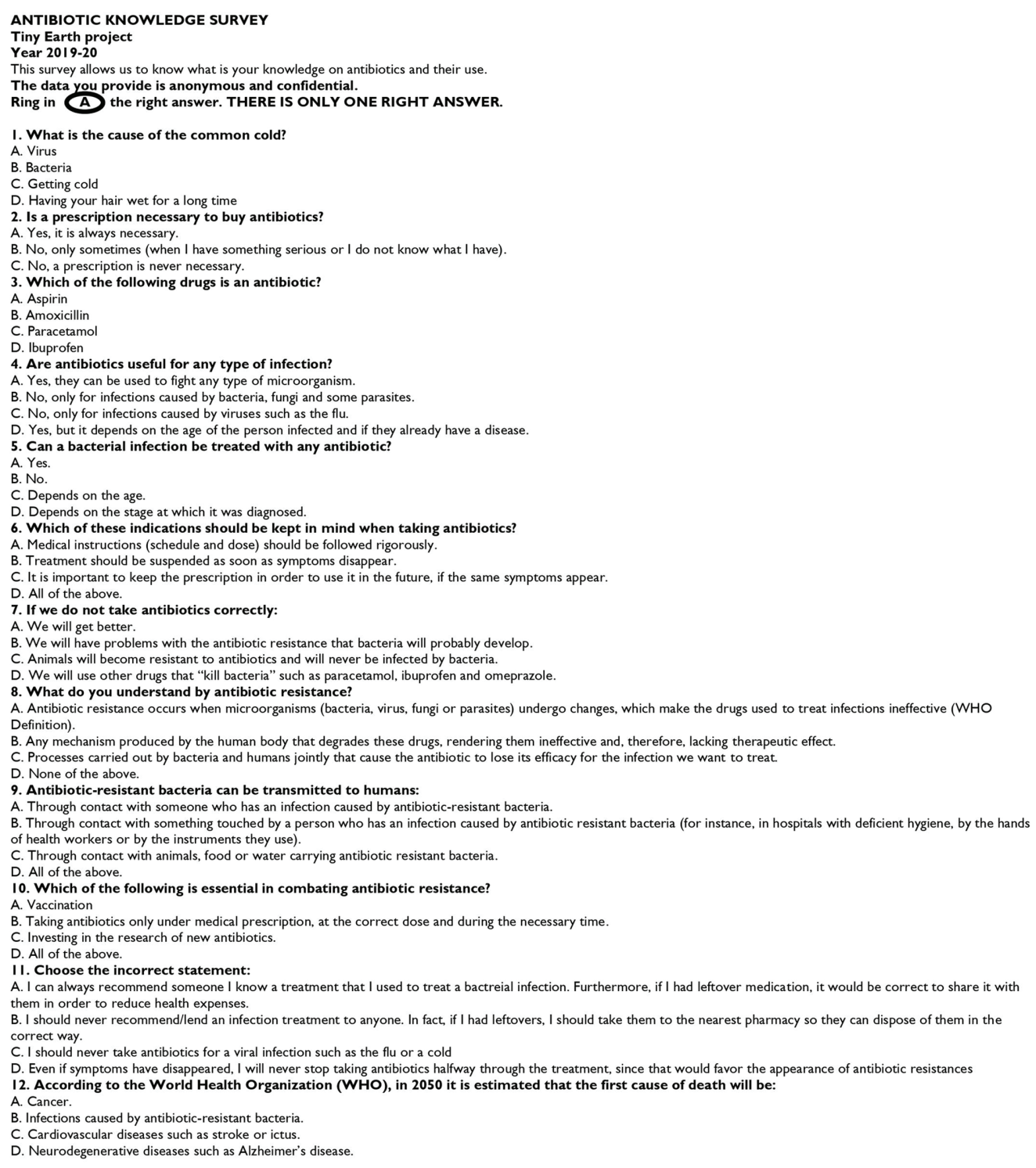

FIGURE 1 | Tiny Earth project's survey (in English) consisting of 12 test questions with a single valid answer.

to carry out the surveys anonymously in order not to exert added pressure to students and preserve the relaxed albeit rigorous character of the activities carried out.

Statistical parameters (such as mean, standard deviation, and variances) were calculated using the Microsoft Excel 2016 program. The Fisher-Snedecor test (F-test) was used to analyze the equality of the variances and the Student's $t$-test was used to determine statistical significances, both tests performed at 95\% confidence interval (CI).

\section{RESULTS}

After analyzing the survey results, we observed $67.6 \%(8.11 / 12)$ of success at the beginning and $81.2 \%(9.74 / 12)$ at the end of the project. These data indicate that students correctly answered an average of 1.64 more questions after completing the practical sessions of the project (Figure 2). The statistical data reveal that there are significative differences at 95\% CI when comparing the overall results at the beginning and at the end of the project (Table 1).

When we analyze the results before and after the project, we highlight the following data: to question 1, "What is the cause of the common cold?" 55.0\% was correctly answered at the beginning and $64.0 \%$ at the end of the practical sessions (Figure 3). To question 2, "Is a prescription necessary to buy antibiotics?" $62.1 \%$ was correctly answered at the beginning and $90.6 \%$ at the end of the practical sessions (Figure 4). To question 4, "Are antibiotics useful for any type of infection?", $70.2 \%$ was correctly answered at the beginning and $83.2 \%$ at 


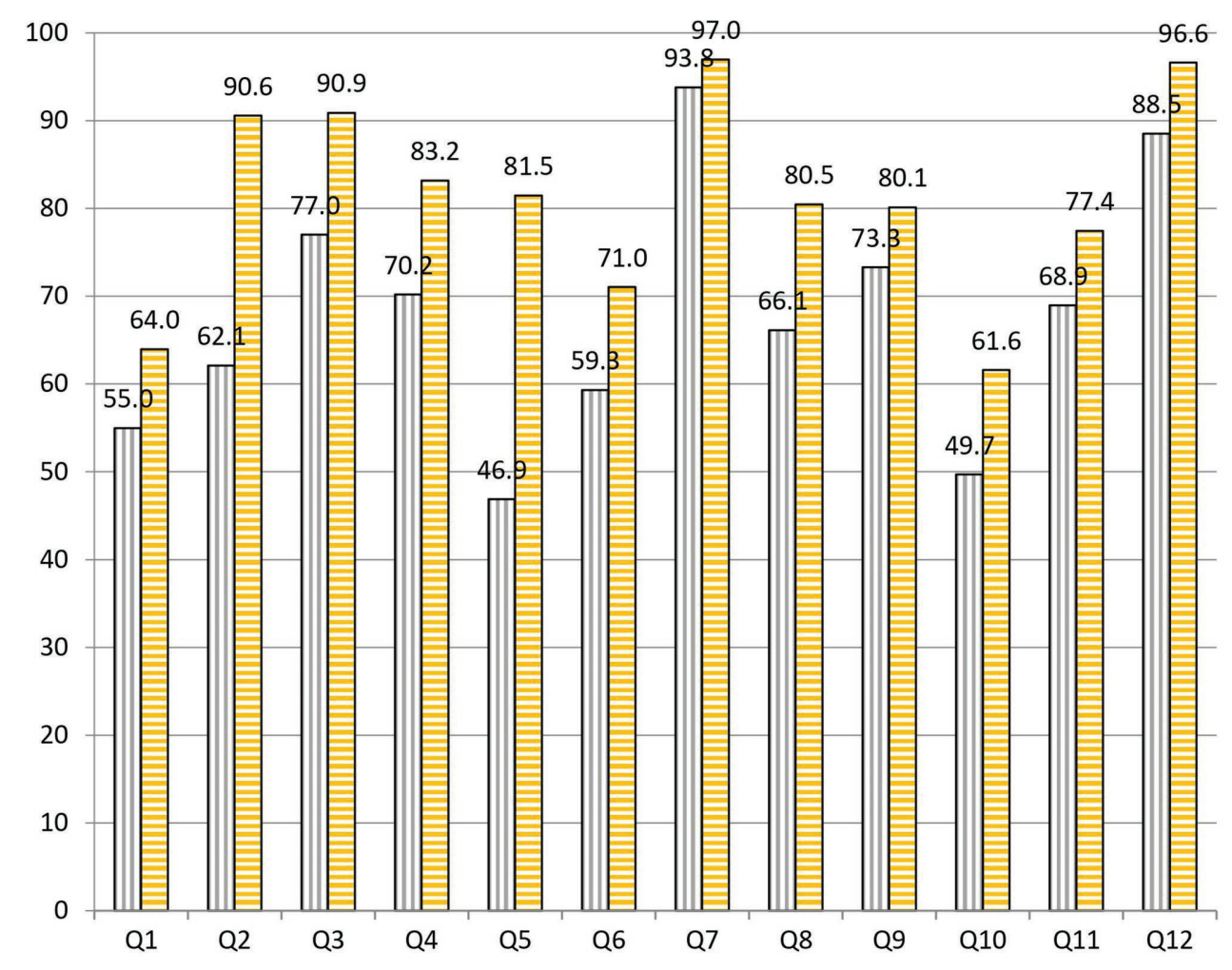

FIGURE 2 | Percentages of correct answers to the 12 questions of the test carried out by pre-university students at the start (purple bars with vertical stripes) and at the end (yellow bars with horizontal stripes) of the Tiny Earth project during the courses 2017-2020.

the end of the practical sessions (Figure 5). To question 5, "Can a bacterial infection be treated with any antibiotic?" $46.9 \%$ was correctly answered at the beginning and $81.5 \%$ at the end of the practical sessions (Figure 6). To question 6, "Which of these indications should be kept in mind when taking antibiotics?," $59.3 \%$ was correctly answered at the beginning and $71.0 \%$ at the end of the practical sessions (Figure 7). To question 8 , "What do you understand by antibiotic resistance?", $66.1 \%$ was correctly answered at the beginning and $80.5 \%$ at the end of the practical sessions (Figure 8). To question 10, "Which of the following is essential in combating antibiotic resistance?", $49.7 \%$ was correctly answered at the beginning and $61.6 \%$ at the end of the practical sessions (Figure 2). The differences in the results before and after the project have proven to be statistically significant at $95 \%$ CI for questions 2 and 8 (Table 1).

\section{DISCUSSION}

From the results of the survey, in which there has been an increase close to $14 \%$ when comparing the number of questions answered correctly at beginning and at the end of the sessions, we can affirm that there has been a significant overall improvement in scientific knowledge from pre-university students participating in this project.
Nevertheless, we do believe that the results obtained in some of the questions asked deserve special attention, either because the difference in the correct answers to a specific question has been negligible, or because this difference has been especially noteworthy.

In question 1, "What is the cause of common cold?" a slight drop (1.1\%) was detected between the answers at the beginning $(50.0 \%)$ and at the end $(48.9 \%)$ of the project during the course 2017-2018 (Figure 3). A possible explanation for these data would be that, having carried out sessions dedicated mainly to bacteria, it might had influenced the perception that diseases are always caused by bacteria. We felt that the results on question 1 were too low on the first course, so in later editions, we tried to deepen our explanation regarding other diseases caused by other microorganisms, which gave place to a significant rise in the percentage of correct answers (10.0\% in $2018-2019$ and $17.1 \%$ in $2019-2020)$. We could say that the explanation was more efficient or effective in the following courses since, without changing it, it was more emphasized and better understood.

Question 2, "Is a prescription necessary to buy antibiotics?," underwent a very considerable change with a $28.5 \%$ overall increase in correct answers given before and after the project (Figure 4). These data are probably due to the emphasis shown by Tiny Earth TAs and Tiny Earth PIs about the risks, both for the patient and for society, associated with the sale of 
TABLE 1 | Statistical parameters at 95\% confidence interval of the comparison between results obtained at the start and at the end of the project.

\begin{tabular}{|c|c|c|c|c|c|c|c|}
\hline & Standard deviation & Variance & $F$-test & Variance equality & Weighted variance & $t$-test & Significative differences \\
\hline Q1 start & 5.048 & 16.988 & \multirow{2}{*}{5.855} & \multirow{2}{*}{ Equal } & \multirow{2}{*}{87.345} & \multirow{2}{*}{1.131} & \multirow{2}{*}{ No } \\
\hline Q1 end & 12.215 & 99.472 & & & & & \\
\hline Q2 end & 4.568 & 13.909 & 5.861 & Equal & 71.570 & 4.200 & Yes \\
\hline Q3 start & 10.005 & 66.735 & \multirow{2}{*}{15.951} & \multirow{2}{*}{ Equal } & \multirow{2}{*}{53.189} & \multirow{2}{*}{2.378} & \multirow{2}{*}{ No } \\
\hline Q3 end & 2.505 & 4.184 & & & & & \\
\hline Q5 end & $\begin{array}{r}37.219 \\
3.091\end{array}$ & 6.369 & 144.997 & Unequal & 697.395 & 2.133 & No \\
\hline Q6 start & 5.698 & 21.645 & \multirow{2}{*}{18.052} & \multirow{2}{*}{ Equal } & \multirow{2}{*}{309.290} & \multirow{2}{*}{0.783} & \multirow{2}{*}{ No } \\
\hline Q6 end & 24.210 & 390.741 & & & & & \\
\hline Q7 start & 2.211 & 3.259 & \multirow{2}{*}{5.388} & \multirow{2}{*}{ Equal } & & & \\
\hline Q7 end & 0.952 & 0.605 & & & 2.898 & 2.481 & No \\
\hline Q8 start & 4.018 & 10.765 & 2120 & Erunl & 25188 & 3512 & Yoe \\
\hline Q10 end & 9.059 & 54.711 & & & & & \\
\hline Q11 start & 13.293 & 117.802 & 3371 & Equal & 114561 & 10 & \\
\hline Q11 end & 7.240 & 34.946 & $3.3 / 1$ & Equal & 114.561 & 1.020 & No \\
\hline Q12 start & 5.389 & 19.358 & & & & & \\
\hline Q12 end & 1.350 & 1.215 & 15.928 & Equal & 15.430 & 2.327 & No \\
\hline Overall start & 3.818 & 9.717 & 9.165 & & & & \\
\hline Overall end & 1.261 & 1.060 & 9.165 & Equal & 8.083 & 5.998 & Yes \\
\hline
\end{tabular}

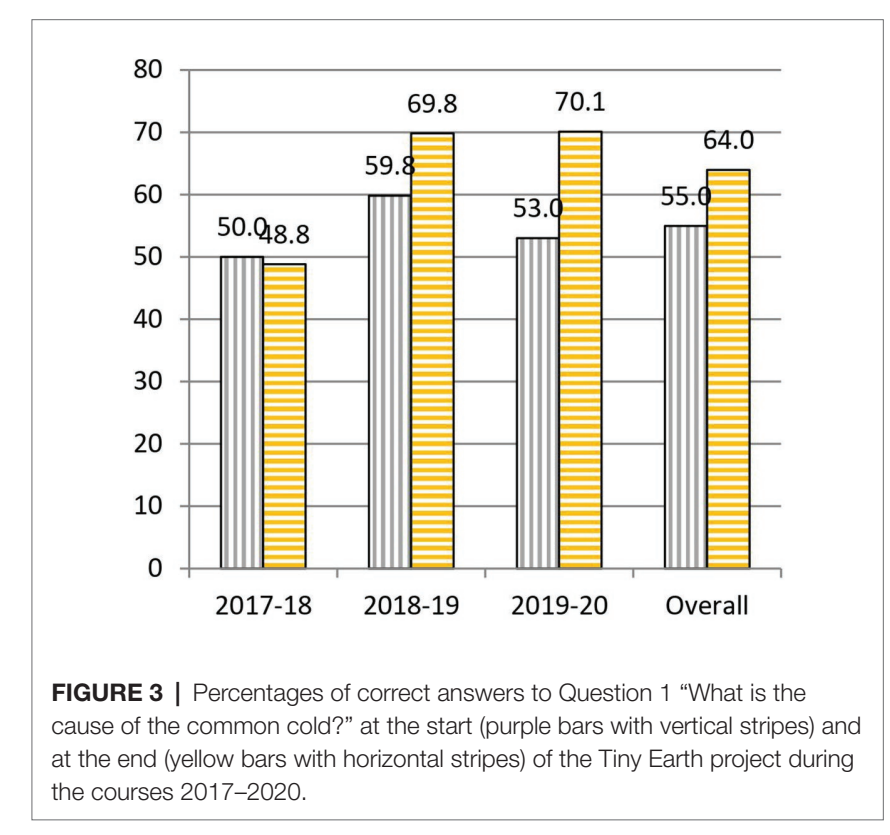

antibiotics without a prescription (Guinovart et al., 2018). We would like to highlight that, year after year, the percentage of correct answers at the end has not ceased to increase (85.7\% in $2017-2018,90.5 \%$ in $2018-2019$, and $94.8 \%$ in 2019-2020). Thus, we can conclude that the tendency of the gap between the percentage of correct answers before and after the project to shrink has more to do with the fact that students had a better knowledge on this question to

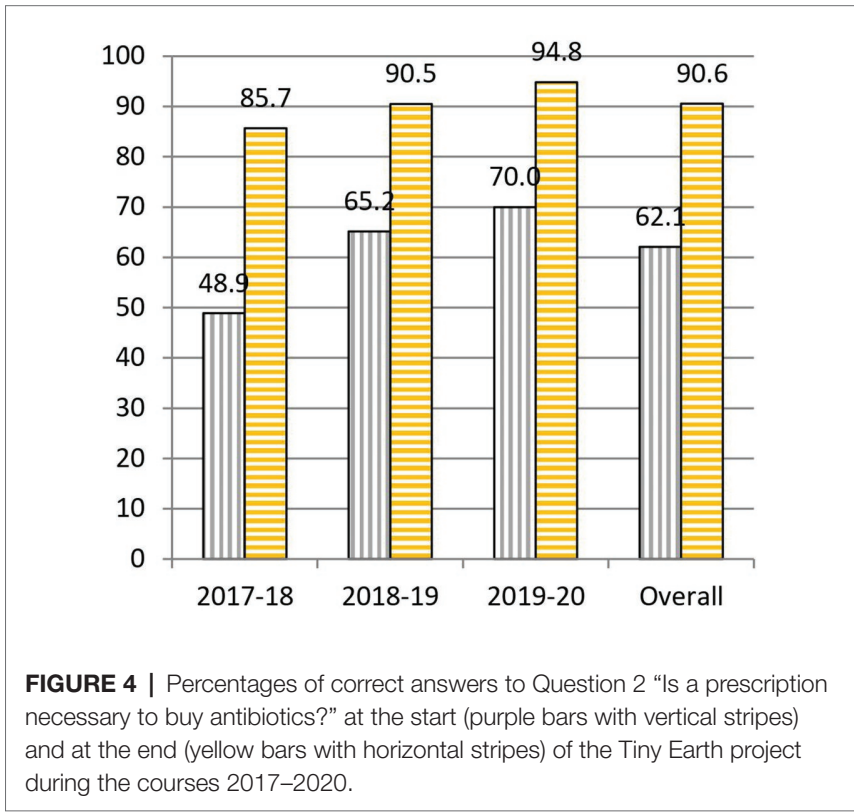

begin with $(48.9 \%$ of correct answers at the beginning of course $2017-2018,65.2 \%$ in $2018-2019$, and $70.0 \%$ in 2019-2020).

Another question that underwent a remarkable change, with a $13.0 \%$ increase in correct answers before and after the project was question 4, "Are antibiotics useful for any type of infection?" (Figure 5). Behind this improvement could be the continuous reminder by Tiny Earth TAs and Tiny Earth PIs throughout 


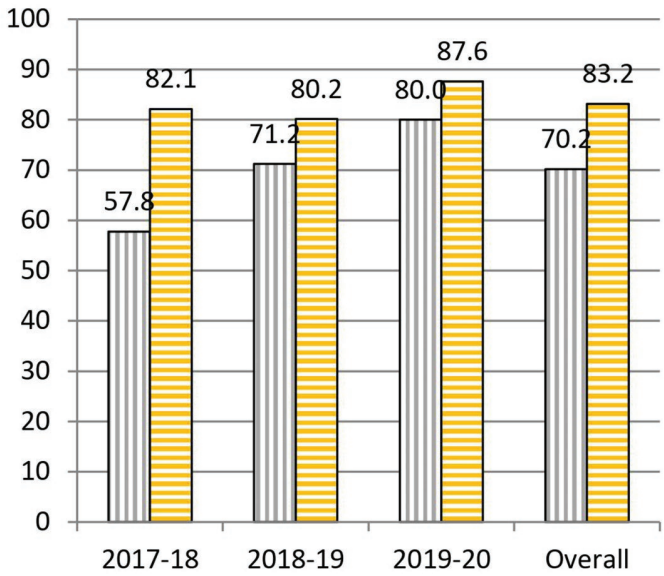

FIGURE 5 | Percentages of correct answers to Question 4 "Are antibiotics useful for any type of infection?" at the start (purple bars with vertical stripes) and at the end (yellow bars with horizontal stripes) of the Tiny Earth project during the courses 2017-2020.

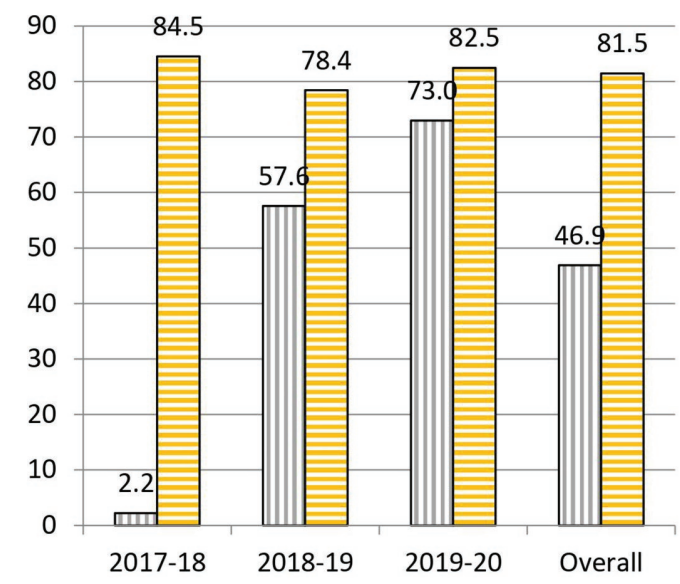

FIGURE 6 | Percentages of correct answers to Question 5 "Can a bacterial infection be treated with any antibiotic?" at the start (purple bars with vertical stripes) and at the end (yellow bars with horizontal stripes) of the Tiny Earth project during the courses 2017-2020. all practical sessions that antibiotics are indeed not useful for all infections. Similarly to question 2 , even though the percentage of correct answers at the end of the project was quite high $(82.1 \%$ in $2017-2018,80.2 \%$ in $2018-2019$, and $87.6 \%$ in 2019-2020), the general knowledge about this question before the project grew year after year $(57.8 \%$ in $2017-2018,71.2 \%$ in $2018-2019$, and $80.0 \%$ in 2019-2020), reason why yearly gaps have decreased.

In question 5, "Can a bacterial infection be treated with any antibiotic?", there has been a striking increase (34.6\%) in the percentage of correct answers before and after the project (Figure 6). This could be due to the emphasis shown

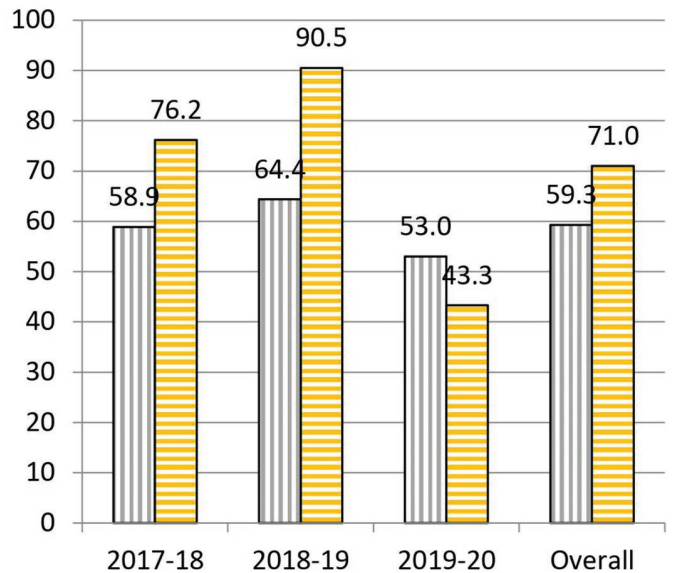

FIGURE 7 | Percentages of correct answers to Question 6 "Which of these indications should be kept in mind when taking antibiotics?" at the start (purple bars with vertical stripes) and at the end (yellow bars with horizontal stripes) of the Tiny Earth project during the courses 2017-2020.

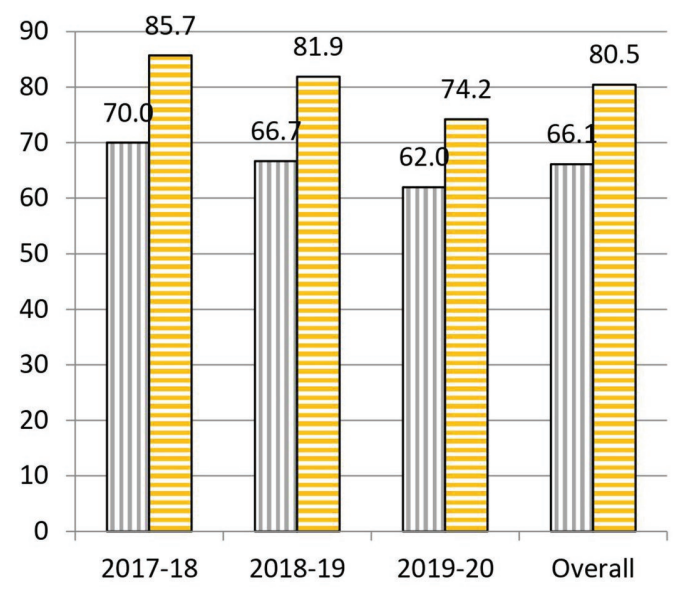

FIGURE 8 | Percentages of correct answers to Question 8 "What do you understand by antibiotic resistance?" at the start (purple bars with vertical stripes) and at the end (yellow bars with horizontal stripes) of the Tiny Earth project during the courses 2017-2020. during the project, in which we explained that not all bacteria are alike, that they can cause various and very different infectious diseases, in addition to the own experience that pre-university students have had when viewing the different degrees of antibiosis against the same bacteria in the lab. A similar pattern to question 4 has been obtained. The percentage of correct answers at the end of the project were quite high (84.5\% in $2017-2018,78.4 \%$ in $2018-2019$, and $82.5 \%$ in 2019-2020), the general knowledge about this question before the project grew year after year $(2.2 \%$ in $2017-2018,57.6 \%$ in $2018-2019$, and $73.0 \%$ in $2019-2020$ ), reason why yearly gaps have also decreased. 
In question 6, "Which of these indications should be kept in mind when taking antibiotics?", there has been an overall increase of $11.7 \%$ correctly answered questions between the beginning and the end of the practical sessions (Figure 7). However, if we focus on the yearly data, very good results were obtained in the first two courses $(17.3 \%$ increase in 2017-2018 and 26.1\% in 2018-2019), but there was a significant drop $(9.7 \%)$ of correct answers between the beginning and the end of this course's project. This result serves as a lesson to not to forget the importance of the rational use of antibiotics. Therefore, we should put a stronger emphasis on this matter in the coming years.

In question 8, "What do you understand by antibiotic resistance?," there has been an overall increase of $14.3 \%$ in correct answers from the beginning to the end of the practical sessions (Figure 8). One of the reasons for these good results might be, besides the theoretical explanations on the concept of resistance given throughout the project, the fact that they have been able to recognize resistances visually by observation of inhibition halos.

In question 10, "Which of the following is essential in combating antibiotic resistance?," there has been an overall increase of $11.9 \%$ in correct answers from the beginning to the end of the practical sessions (Figure 2). Even though there have been questions with less improvement between the beginning and the end, it is the question with the lowest success rate at the end of the project $(61.6 \%)$. This might be due to the fact that it is a question in which all the answers are correct and, therefore, they must have learned all the concepts stated in the question.

We must say that our first goal was not to obtain uniform results from the tests. However, after analyzing the results on our first year, we tried to do some improvements in our presentations based on that information and, thus, results became more uniform for the last 2 years. However, we sincerely hope that teachers who may want to start a similar project could benefit from our findings.

We should also note that in schools where the number of students has been lower, both the results and collaboration have been more positive because the sessions were held more calmly and with a more personalized attention. In schools where there have been more students, although the results have also been satisfactory, attention could not have been so individualized. These results are consistent with various studies showing that while a significant proportion of the general public still believe that antibiotics are an effective treatment for cold symptoms, they also report increased awareness of antibiotic resistance (European Commission, 2013; Carter et al., 2016).

Chronic infectious diseases such as HIV and tuberculosis and emerging infections with the potential for rapid expansion such as the 2014 Ebola epidemic and the 2020 COVID-19 pandemic remain a substantial global health threat to mankind (Shahmanesh et al., 2020). Infectious diseases have profound effects beyond health, especially on local and global economies, which intensifies existing socioeconomic fragilities (United Nations Development Programme and International Federation of Red
Cross and Red Crescent Societies, 2017). However, the prevalence of antimicrobial resistance grows by the year and we will soon be speaking about millions of deaths from antibiotic-resistant infections (Collignon et al., 2018).

We think that there is an urgent need for educational and awareness programs integrating methods to optimize the prevention of, and response to, infectious diseases. This might mean training science teachers and broadcasters to improve their dissemination on human health (Samet and Woodward, 2019).

\section{CONCLUSION}

The global experience of the Tiny Earth project has been very positive. Participation in the Tiny Earth project has positively contributed to the development of scientific interest, the awareness on the proper use of antibiotics, and the emergence of resistances in pre-university studies, as well as improved their skills in the laboratory.

Likewise, in view of the results obtained with the survey, we can affirm that the students participating in this project have improved their scientific knowledge. Besides, these newly learned skills may also be transmitted to their social environment, thus improving the overall awareness of this issue. We can also conclude that the Tiny Earth project has awakened and expanded the scientific training and interest in students.

We would also like to highlight the need for new approaches in order to reach the general public in the field of infectious diseases.

\section{DATA AVAILABILITY STATEMENT}

The original contributions presented in the study are included in the article/supplementary material, and further inquiries can be directed to the corresponding author.

\section{ETHICS STATEMENT}

Ethical approval was not provided for this study on human participants because no personal data was collected. We asked for informed consent given that the students that participated in the project where under 18 years old. Written informed consent to participate in this study was provided by the participants' legal guardian/next of kin.

\section{AUTHOR CONTRIBUTIONS}

M-TP-G was responsible for the project design, conception and management and the integrity of the work, and overall supervision. JB-B, BS-G, CG-R, and M-TP-G performed the practicals. EM-C was responsible for the broadcasting of the project. JB-B wrote the first draft of the manuscript. BS-G, CG-R, and EM-C wrote sections of the manuscript. 
All authors contributed to interpretation of the data, manuscript revision, read, and approved the manuscript.

\section{FUNDING}

This project was supported by grants CEU INNOVA Programme (PI14B-SV-17, PI09B-SV-18, PI68B-SV-19-20) from Universidad CEU Cardenal Herrera.

\section{REFERENCES}

Bentzien, J., Bharadwaj, R., and Thompson, D. C. (2015). Crowdsourcing in pharma: a strategic framework. Drug Discov. Today 20, 874-883. doi: 10.1016/j. drudis.2015.01.011

Brabham, D. C., Ribisl, K. M., Kirchner, T. R., and Bernhardt, J. M. (2014). Crowdsourcing applications for public health. Am. J. Prev. Med. 46, 179-187. doi: 10.1016/j.amepre.2013.10.016

Carter, R. R., Sun, J., and Jump, R. L. (2016). A survey and analysis of the American Public's perceptions and knowledge about antibiotic resistance. Open Forum Infect. Dis. 3:ofw112. doi: 10.1093/ofid/ofw112

Caruso, J. P., Israel, N., Rowland, K., Matthew, J., Lovelace, M. J., and Saunders, M. J. (2016). Citizen science: the Small World Initiative improved lecture grades and California critical thinking skills test scores of nonscience major students at Florida Atlantic University. J. Microbiol. Biol. Educ. 17, 156-162. doi: 10.1128/jmbe.v17i1.1011

Cisneros Herreros, J. M., and Peñalva Moreno, G. (2018). La crisis de los antibióticos: profesionales sanitarios, ciudadanos y políticos, todos somos responsables. Enferm. Infecc. Microbiol. Clin. 36, 259-261. doi: 10.1016/j.eimc.2018.02.002

Collignon, P., Beggs, J. J., Walsh, T. R., Gandra, S., and Laxminarayan, R. (2018). Anthropological and socioeconomic factors contributing to global antimicrobial resistance: a univariate and multivariable analysis. Lancet Planet. Health 2, e398-e405. doi: 10.1016/S2542-5196(18)30186-4

Davies, J., and Davies, D. (2010). Origins and evolution of antibiotic resistance. Microbiol. Mol. Biol. Rev. 74, 417-433. doi: 10.1128/MMBR.00016-10

Davis, E., Sloan, T., Aurelius, K., Barbour, A., Bodey, E., Clark, B., et al. (2017). Antibiotic discovery throughout the Small World Initiative: a molecular strategy to identify biosynthetic gene clusters involved in antagonistic activity. MicrobiologyOpen 6:e00435. doi: 10.1002/mbo3.435

European Commission (2013). Special Eurobarometer 407. Antimicrobial resistance. Report. Available at: http://ec.europa.eu/health/antimicrobial_ resistance/docs/ebs_407_en.pdf (Accessed April 15, 2020).

Guinovart, M. C., Figueras, A., and Llor, H. (2018). Selling antimicrobials without prescription-far beyond an administrative problem. Enferm. Infecc. Microbiol. Clin. 36, 290-292. doi: 10.1016/j.eimc.2016.10.006

Handelsman, J., Tsang, T., and Hernandez, S. (2016). Small World Initiative: A research guide to microbial and chemical diversity. New Haven: Small World Initiative Press.

Hover, B. M., Kim, S. H., Katz, M., Charlop-Powers, Z., Owen, J. G., Ternei, M. A., et al. (2018). Culture-independent discovery of the malacidins as calciumdependent antibiotics with activity against multidrug-resistant Gram-positive pathogens. Nat. Microbiol. 3, 415-422. doi: 10.1038/s41564-018-0110-1

Klein, E. Y., Van Boeckel, T. P., Martinez, E. M., Pant, S., Gandra, S., Levin, S. A., et al. (2018). Global increase and geographic convergence in antibiotic consumption between 2000 and 2015. Proc. Natl. Acad. Sci. U. S. A. 115, E3463-E3470. doi: 10.1073/pnas.1717295115

Lewis, K. (2017). New approaches to antimicrobial discovery. Biochem. Pharmacol. 134, 87-98. doi: 10.1016/j.bcp.2016.11.002

O'Neill, J. (2015). Antimicrobials in agriculture and the environment: reducing unnecessary use and waste. The review on antimicrobial resistance. Available at: https://amr-review.org/sites/default/files/Antimicrobials\%20 in $\% 20$ agriculture $\% 20$ and $\% 20$ the $\% 20$ environment $\% 20$-\%20Reducing $\% 20$ unnecessary\%20use\%20and\%20waste.pdf (Accessed April 15, 2020).

\section{ACKNOWLEDGMENTS}

We would like to thank the schools Deutsche Schule Valencia, American School of Valencia, Caxton College, CEU San Pablo, Edelweiss, Santa María del Puig, and San Pedro Pascual for their participation, as well as their teachers and students participating in the Tiny earth project. We thank the support and encouragement from the Teaching and Communication Division of the Spanish Microbiology Society (D+D SEM) and the MicroMundo net.

Pernaute, L., and Jiménez, V. (2017). Small World Initiative: educando para combatir la resistencia a los antibióticos. PharmaTech 32, 74-80. Available at: https://www.pharmatech.es/kiosco/revista32/visor (Accessed April 22, 2020).

Phillips, I., Casewell, M., Cox, T., De Groot, B., Friis, C., Jones, R., et al. (2004). Does the use of antibiotics in food animals pose a risk to human health? A critical review of published data. J. Antimicrob. Chemother. 53, 28-52. doi: 10.1093/jac/dkg483

Prigitano, A., Romanò, L., Auxilia, F., Castaldi, S., and Tortoano, A. M. (2018). Antibiotic resistance: Italian awareness survey 2016. J. Infect. Public Health 11, 30-34. doi: 10.1016/j.jiph.2017.02.010

Samet, J. M., and Woodward, A. (2019). On being an epidemiologist. Am. J. Epidemiol. 188, 818-824. doi: 10.1093/aje/kwy279

Scaioli, G., Gualano, M. R., Gili, R., Masucci, S., Bert, F., and Siliquini, R. (2015). Antibiotic use: a cross-sectional survey assessing the knowledge, attitudes and practices amongst students of a school of medicine in Italy. PLoS One 10:e0122476. doi: 10.1371/journal.pone.0122476

Shahmanesh, M., Harling, G., Coltart, C. E. M., Bailey, H., King, C., Gibbs, J., et al. (2020). From the micro to the macro to improve health: microorganism ecology and society in teaching infectious disease epidemiology. Lancet Infect. Dis. 20, e142-e147. doi: 10.1016/\$1473-3099(20)30136-5

Tiny Earth (2018). Available at: https://tinyearth.wisc.edu (Accessed June 22, 2020).

United Nations Development Programme and International Federation of Red Cross and Red Crescent Societies (2017). A socio-economic impact assessment of the Zika virus in Latin America and the Caribbbean: with a focus on Brazil, Colombia and Suriname. Available at: http://www.undp.org/content/ dam/undp/library/HIV-AIDS/UNDP-Zika-04-03-2017-English-WEB.pdf (Accessed June 11, 2020).

Valderrama, M. J., González-Zorn, B., de Pablo, P. C., Díez-Orejas, R., Fernández-Acero, T., Gil-Serna, T., et al. (2018). Educating in antimicrobial resistance awareness: adaptation of the Small World Initiative program to service-learning. FEMS Microbiol. Lett. 365:fny161. doi: 10.1093/femsle/ fny 161

World Health Organization (2015). Antibiotic resistance: multi-country public awareness survey. Available at: http://apps.who.int/iris/bitstream/10665/19446 0/1/9789241509817eng.pdf?ua=1 (Accessed April 22, 2020).

World Health Organization (2016). Meeting the challenge of antimicrobial resistance. Available at: https://www.who.int/antimicrobial-resistance/interagencycoordination-group/IACG_Meeting_challenge_AMR_communication_to_ collective_action_270718.pdf (Accessed April 22, 2020).

Conflict of Interest: The authors declare that the research was conducted in the absence of any commercial or financial relationships that could be construed as a potential conflict of interest.

Copyright (c) 2020 Bueso-Bordils, Suay-García, Galiana-Roselló, Marco-Crespo and Pérez-Gracia. This is an open-access article distributed under the terms of the Creative Commons Attribution License (CC BY). The use, distribution or reproduction in other forums is permitted, provided the original author(s) and the copyright owner(s) are credited and that the original publication in this journal is cited, in accordance with accepted academic practice. No use, distribution or reproduction is permitted which does not comply with these terms. 